
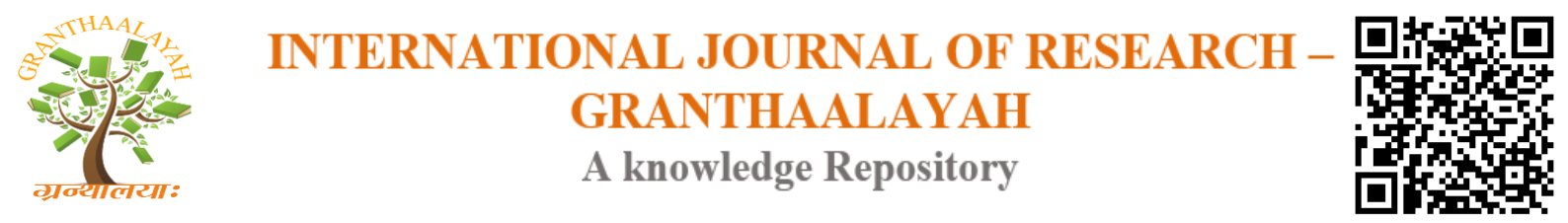

Science

\title{
EXPERIMENTAL STUDY OF THERMAL EFFECT OF DRYING, HEATING, BLOWING MACHINE WITH DIFFERENT STAGE
}

\author{
Aditya Pratap Singh ${ }^{1}$, Disha Dinesh Sahni ${ }^{2}$, Arpit Dubey ${ }^{3}$ \\ 1,2,3 B.E., Jabalpur Engineering College, Jabalpur, INDIA
}

DOI: https://doi.org/10.29121/granthaalayah.v4.i8.2016.2568

\section{ABSTRACT}

Drying is the oldest method of preserving food. The early American settlers dried foods such as corn, apple slices, currants, grapes, and meat. Compared with other methods, drying is quite simple. In fact, you may already have most of the equipment on hand. Dried foods keep well because the moisture content is so low that spoilage organisms cannot grow.

Drying will never replace canning and freezing because these methods do a better job of retaining the taste, appearance, and nutritive value of fresh food. But drying is an excellent way to preserve foods that can add variety to meals and provide delicious, nutritious snacks. One of the biggest advantages of dried foods is that they take much less storage space than canned or frozen foods.

Keywords:

Experimental process, three stage temperature, Drying, Heating.

Cite This Article: Aditya Pratap Singh, Disha Dinesh Sahni, and Arpit Dubey, "EXPERIMENTAL STUDY OF THERMAL EFFECT OF DRYING, HEATING, BLOWING MACHINE WITH DIFFERENT STAGE" International Journal of Research - Granthaalayah, Vol. 4, No. 8 (2016): 104-109.

\section{INTRODUCTION}

Drying food in the oven of a kitchen range, on the other hand, can be very expensive. In an electric oven, drying food has been found to be nine to twelve times as costly as canning it. Food dehydrators are less expensive to operate but are only useful for a few months of the year. A convection oven can be the most economical investment if the proper model is chosen. A convection oven that has a controllable temperature starting at 120 degrees $\mathrm{F}$. and a continuous operation feature rather than a timer-controlled one will function quite well as a dehydrator during the gardening months. For the rest of the year it can be used as a tabletop oven. 


\section{SPEED}

For a good-quality product, vegetables and fruits must be prepared for drying as soon as possible after harvesting. They should be blanched, cooled, and laid out to dry without delay. Foods should be dried rapidly, but not so fast that the outside becomes hard before the moisture inside has a chance to evaporate. Drying must not be interrupted. Once you start drying the food, don't let it cool down in order to start drying again later. Mold and other spoilage organisms can grow on partly dried food.

\section{TEMPERATURE}

During the first part of the drying process, the air temperature can be relatively high, that is, 150 degrees to 160 degrees F. (65 degrees to 70 degrees C.), so that moisture can evaporate quickly from the food. Because food loses heat during rapid evaporation, the air temperature can be high without increasing the temperature of the food. But as soon as surface moisture is lost (the outside begins to feel dry) and the rate of evaporation slows down, the food warms up. The air temperature must then be reduced to about 140 degrees $\mathrm{F}$. (60 degrees $\mathrm{C}$.).

Toward the end of the drying process the food can scorch easily, so you must watch it carefully. Each fruit and vegetable has a critical temperature above which a scorched taste develops. The temperature should be high enough to evaporate moisture from the food, but not high enough to cook the food. Carefully follow directions for regulating temperatures.

\section{HUMIDITY AND VENTILATION}

Rapid dehydration is desirable. The higher the temperature and the lower the humidity, the more rapid the rate of dehydration will be. Humid air slows down evaporation. Keep this in mind if you plan to dry food on hot, muggy summer days. If drying takes place too fast, however, "case hardening" will occur. This means that the cells on the outside of the pieces of food give up moisture faster than the cells on the inside. The surface becomes hard, preventing the escape of moisture from the inside. Moisture in the food escapes by evaporating into the air. Trapped air soon takes on as much moisture as it can hold, and then drying can no longer take place. For this reason, be sure the ventilation around your oven or in your food dryer is adequate.

\section{TYPES OF FOOD TO DRY}

Many kinds of fresh fruits, vegetables, herbs, meat, and fish can be dried. If you have never tried drying food before, though, it's a good idea to experiment first by drying a small quantity in the oven. This way you can see if you like the taste and texture of dried food. At the same time, you can become familiar with the drying process. Fruits are easier to dry than vegetables because moisture evaporates wore easily, and not as much moisture must be removed for the product to keep. Ripe apples, berries, cherries, peaches, apricots, and pears are practical to dry.

Vegetables that are also practical to dry include peas, corn, peppers, zucchini, okra, onions, and green beans. Produce from the supermarket is usually more expensive than and not as fresh as it should be for drying. It is a waste of time and energy to dry vegetables such as carrots that can be 
kept for several months in a cool, dry basement or cellar. Fresh herbs of all types are suitable for drying. The parts of the plant to dry vary, but leaves, seeds, or blossoms usually give the best results. Lean meats such as beef, lamb, and venison can be dried for jerky. Fish also is excellent when dried. Certain foods are not suitable for drying because of their high moisture content. Lettuce, melons, and cucumbers are a few foods that do not dry well.

\section{SUCCESSFUL DRYING}

Don't be surprised to find a variety of suggestions for drying methods, temperatures, and lengths of time. The drying process is simply not as precise as canning and freezing because it involves so many different factors. You may need to use a trial-and-error approach to find what suits you best. Whatever method you use, be sure to remove enough moisture from the final product so that spoilage organisms cannot grow.

When you dry foods, remember the following:

- Cleanliness and sanitation are essential.

- The flavor of dried fruits and vegetables will be somewhat different from that of their fresh, canned, or frozen counterparts.

\section{METHODS}

\section{OVEN DRYING}

Oven drying is the simplest way to dry food because you need almost no special equipment. It is also faster than sun drying or using a food dryer. But oven drying can be used only on a small scale. An ordinary kitchen oven can hold only 4 to 6 pounds of food at one time. Set the oven on the lowest possible setting and preheat to 140 degrees F. (60 C.). Do not use the broiler unit of an electric oven because the food on the top tray will dry too quickly' Remove the unit if it has no separate control. Some gas ovens have a pilot right, which may keep the oven warm enough to dry the food.

It is important to keep the oven temperature at 140 to $160 \mathrm{~F}$. (60 to $70 \mathrm{C}$.). So put an oven thermometer on the top tray about half way back where you can see it easily. Check the temperature about every half hour. Arrange 1 to 2 pounds of prepared food in a single layer on each tray. Put one tray on each oven rack. Allow 1-1/2 inches of space on the sides, front, and back of the trays so that air can circulate all around them in the oven. To stack more trays in the oven, use blocks of wood in the comers of the racks to hold the trays at least I inches apart. Dry no more than four trays of food at a time. A lighter load dries faster than a full load.

Keep the oven door open slightly during drying. A rolled newspaper, a block of wood, or a hot pad will keep the door ajar so that moist air can escape while the heat stays in the oven. Four to six inches for electric ovens or 1 to 2 inches for gas ovens is usually enough space for ventilation, but use a thermometer to check the oven temperature to make sure it stays at $140 \mathrm{~F}$. An electric fan placed in front of the oven door helps to keep the air circulating. 


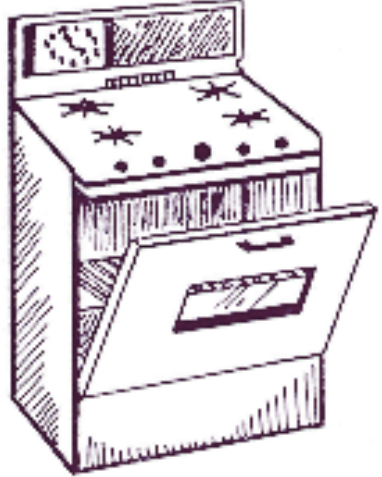

Figure 1: oven drying

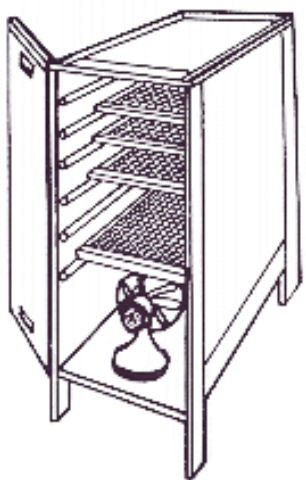

Figure 2: food dryer

\section{FOOD DRYER}

A commercial or homemade food dryer or convection oven provides automatically controlled heat and ventilation. Most households will not need a dryer unless they dry large quantities of food. A food dryer takes less electricity than drying the same amount of food in an electric oven. However, the temperature is usually lower (about 120 degrees F. or 50 C.), so drying takes a little longer than in an oven.

\section{PRETREATMENT}

Almost all kinds of fruit need some treatment before drying. Apples are peeled, cored, and sliced. Fruits with pits, such as peaches and apricots, are usually halved and pitted. Most fruits do not need to be peeled before drying. But the skins of some fruits such as cherries are tough and waxy, so you will have to "crack" the skins first. Fruit should be cut into uniform pieces or slices so that it will dry more evenly. Remember that thin pieces dry faster than thick ones.

\section{CRACKING SKINS}

Blueberries, cherries, grapes, plums, and a few other fruits have relatively tough skins with a wax like coating. The skin must be "cracked" or "checked" in many places to remove the waxy coating and to let the inside moisture come to the surface to evaporate. To crack the skin, put the fruit in-to boiling water for 30 to 60 seconds. Then dip in very cold water. Drain thoroughly on absorbent toweling. We recommend cracking the skins in water rather than dipping the fruit in lye solutions because handling lye can be dangerous.

\section{DRYING}

Spread the prepared vegetables in thin layers on the drying trays. Then stack the trays in the oven or dryer. Make sure to leave at least 1 inches between the trays so that the air can circulate freely around them. If the trays are too close together, drying will take longer. If you are using an oven, keep the door open slightly and use an electric fan. A food dryer is equipped with a fan for ventilation, so close the door. Keep the oven temperature at 140 degrees F. (60 C.). Stir the pieces of vegetables about every half hour so that all surfaces are exposed to the air. Also, shift 
the trays around on the racks periodically because the temperature inside the oven varies somewhat from top to bottom and from front to back.

Vegetables take from 4 to 12 hours to dry. The length of time depends on the kind and amount of food being dried, the method you use (oven or food dryer), and the drying temperature. When sufficiently dry, the vegetables will be hard and brittle. You can test them by hitting a piece with a hammer; the piece should shatter.

\section{SPECIAL HANDLING OF VEGETABLES}

Carrots, turnips, parsnips, rutabagas, and potatoes are better stored fresh than dried. They can be kept for several months in a cellar or basement. Broccoli and asparagus are better frozen than dried because freezing helps preserve their fresh flavor and texture. Combinations of vegetables can be dried at the same time. Just remember that vegetables have different drying times, so some will be dry before others. Vegetables with a strong odor should not be dried at the same time as other vegetables because those with a mild flavor may absorb the strong odor. Salad seasoning ingredients should be dried separately, then mixed and stored together for delightful blends. A good mix for salads might include tiny bits of carrots, tomatoes, celery, onion, spinach, green peppers, and parsley. Soup vegetables should always be dried separately. Then you can combine them in different ways so that you will have a vast variety of gourmet soups at your fingertips. You can blend the flavors to suit your own taste; just let your imagination be your guide. These home-prepared combinations will be much cheaper than those available commercially.

\section{BLOWER}

Air blowers generally use centrifugal force to propel air forward. Inside a centrifugal air blower is a wheel with small blades on the circumference and a casing to direct the flow of air into the center of the wheel and out toward the edge. The design of the blades will affect how the air is propelled and how efficient the air blower is. Blade designs in air blowers are classified as forward-curved, backward-inclined, backward-curved, radial and airfoil.

\section{FORWARD-CURVED AIR BLOWERS}

Forward-curved blowers are impulse devices with blades that are curved in the direction of rotation. The blower accelerates air to a high velocity while rotating at a low speed. Forwardcurved blower wheels spin at relatively low speeds and produce high volumes of air at low static pressures. This type of blower is incapable of operating at the speeds necessary to create high static pressures because of its lightweight construction. Still, forward-curved blowers are the most common type of air blower because they propel the most air volume in relation to blower size and speed.

\section{BACKWARD-INCLINED AND BACKWARD-CURVED AIR BLOWERS}

A backward-inclined blower, operating at roughly twice the speed of a forward-curved air blower, has flat blades that slant away from the direction of travel. This type of blower is highly 
efficient (low horsepower requirement) and has a rugged construction suitable for high static pressure applications. This type of air blower is best used in locations where the air is either clean or mildly contaminated. Similar to this style is a backward-curved air blower. The blades of a backward-curved blower are a single thickness throughout and curve away from the direction of travel. These blades are sturdier than backward-inclined blades and can be used in corrosive and erosive environments.

\section{RADIAL AIR BLOWERS}

Radial blowers are designed for industrial use in small exhaust systems. These air blowers are capable of handling air that contains bits of dirt, grit, lint and other foreign particles while still maintaining a high-pressure supply of air for conveying and cooling. Their use in particle-laden air means that this type of blower is generally designed to be self-cleaning. Radial air blowers have the lowest efficiency levels because the blades have no curve or lean and are perpendicular to the wheel's rotation. Think of a paddleboat racing a boat with an outboard motor. No matter how fast the paddle spins, it will not catch up to the boat with the outboard motor.

\section{REFERENCE}

[1] G. Srivastava, A technical note on - performance testing of a solar box cooker provided with sensible storage material on the surface of absorbing plate, Int. J. Renew. Energy Technol. 3 (2) (2012) 165-173.

[2] Lawrence Taylor, John De Vries, Stephen Heibein, Solar application of thermal energy storage, Final Report, H-C0199-79-753F, US Department of nEnergy, Hitman associates Inc., Columbia, MD 21045, 1979.

[3] H.O. Pierson, Handbook of carbon graphite, diamond and fullerenesproperties, processing and applications, Noyes publications, Park Ridge, NJ, nUSA, 2008.

[4] K. Sopian, S. Mat, Fabrication and experimental investigation of nPCM capsules integrated in solar air heater, Am. J. Environ. Sci. 7 (6) (2011) n542-546.

[5] P.T. Saravanakumar, K. Mayilsamy, Forced convection flat plate solar air nheaters with and without thermal storage, J. Sci. Ind. Res. 69 (2010) 966-968.

[6] Ranjit Singh, R.P. Saini, J.S. Saini, Models for predicting thermal performance of npacked bed energy storage system for solar air heaters - a review, Open Fuels Energy Sci. J. 2 (2009) 47-53.

[7] Ram Chandra, M.S. Sodha, Testing procedures for solar air heaters: a review, nEnergy Conv. Manage. 32 (1) (1991) 11-33.

[8] S.B. Prasad, J.S. Saini, K.M. Singh, Investigation of heat transfer and friction characteristics of packed bed solar air heater using wire mesh as packing nmaterial, Econ. Sol. Energy Conserv. Syst. 83 (2009) 773-783.

[9] S.S. Krishnananth, K.K. Murugavel, Experimental study on double pass solar air nheater with thermal energy storage, J. King Saud Univ. Eng. Sci. (2012), in nbpress, http://dx.doi.org/10.1016/j.jksues.2012.05.004.

[10] S. Karthikeyan, R. Velraj, Numerical and experimental investigation of the nbcharging and discharging processes in a packed bed PCM based storage unit for nair heating applications, Eur. J. Sci. Res. 66 (1) (2011) 105-119. 